Proceedings of the Eighth Integrated History \& Philosophy of Science Conference (\&HPS8)

\title{
Ontology and values anchor indigenous and grey nomenclatures: a case study in lichen naming practices among the Sámi, Sherpa, Scots, and Okanagan*
}

\author{
Catherine Kendig \\ Department of Philosophy \\ Michigan State University \\ kendig@msu.edu
}

\begin{abstract}
:
Ethnobotanical research provides ample justification for comparing diverse biological nomenclatures and exploring ways that retain alternative naming practices. However, how (and whether) comparison of nomenclatures is possible remains a subject of discussion. The comparison of diverse nomenclatural practices introduces a suite of epistemic and ontological difficulties and considerations. Different nomenclatures may depend on whether the communities using them rely on formalized naming conventions; cultural or spiritual valuations; or worldviews. Because of this, some argue that the different naming practices may not be comparable if the ontological commitments employed differ. Comparisons between different nomenclatures cannot assume that either the naming practices or the object to which these names are intended to apply identifies some universally agreed upon object of interest. Investigating this suite of philosophical problems, I explore the role grey nomenclatures play in classification. 'Grey nomenclatures' are defined as those that employ names that are either intentionally or accidently non-Linnaean. The classification of the lichen thallus (a symbiont) has been classified outside the Linnaean system by botanists relying on the International Code of Nomenclature for algae, fungi, and plants (ICN). But, I argue, the use of grey names is not isolated and does not occur exclusively within institutionalized naming practices. I suggest, 'grey names' also aptly describe nomenclatures employed by indigenous communities such as the Sámi of Northern Finmark, the Sherpa of Nepal, and the Okanagan First Nations. I pay particular attention to how naming practices are employed in these communities; what ontological commitments they hold; for what purposes are these names used; and what anchors the community's nomenclatural practices. Exploring the history of lichen naming and early ethnolichenological research, I then investigate the stakes that must be considered for any attempt to preserve, retain, integrate, or compare the knowledge contained in both academically formalized grey names and indigenous nomenclatures in a way that preserves their source-specific informational content.
\end{abstract}

\footnotetext{
${ }^{*}$ A revised version of this paper has been published in the journal Studies in History and Philosophy of Science Part $C$. The full citation is: Kendig, Catherine (2020). Ontology and values anchor indigenous and grey nomenclatures: a case study in lichen naming practices among the Sámi, Sherpa, Scots, and Okanagan. Studies in History and Philosophy of Science Part C: Studies in History and Philosophy of Biological and Biomedical Sciences 84 (101340): 1-11. https://doi.org/10.1016/j.shpsc.2020.101340
} 


\section{Introduction}

A biological nomenclature - whether it be one that is academically institutionalized, indigenous, or vernacular - provides a system of labelling that applies to those objects that are of interest. A name, affixed to a particular object of interest, contains information about what is known, what is valued, and how it is used (Bowker and Star 1999, Rasmussen and Akulukjuk 2009). Past and current ethnobotanical research provides ample justification for comparing diverse nomenclatures and exploring ways that retain alternative naming practices as well as the knowledge encoded within them from different communities. However, how (and whether) comparison of nomenclatures is possible remains a subject of discussion.

The comparison of diverse nomenclatural practices introduces a suite of epistemic and ontological difficulties and considerations. For example, how different nomenclatures name objects of interests may depend on whether the communities using them rely on formalized naming conventions; pragmatic or economic interests; cultural or spiritual valuations; or share particular worldviews. Because of this, some might argue that the information contained within different naming practices may not be comparable from one community of users to the next if the ontological commitments employed in the naming or the purpose for naming differs. As such, comparisons between different nomenclatures cannot assume that either the naming practices or the object to which these names are intended to apply identifies some universally agreed upon object of interest. Investigating this suite of philosophical problems, I explore the role grey nomenclatures play in classification. 'Grey nomenclatures' are defined as those that employ names that are either intentionally or accidentally non-Linnaean (Minelli 2017). For instance, the classification of the lichen thallus (a symbiont) has been and continues to be classified outside the Linnaean system by botanists relying on the International Code of Nomenclature for algae, fungi, and plants (ICN). But the use of grey names is not isolated and does not occur exclusively within institutionalized naming practices. I suggest, 'grey names' also aptly describe nomenclatures employed by indigenous communities such as the Sámi of Northern Finmark, the Sherpa, Limbu, Lama and Rai of Nepal, and the Okanagan First Nations. In this paper, I explore how lichens are named and classified in each of these diverse communities. I do this by paying particular attention to how naming practices are employed in these communities; what ontological commitments they hold; for what purposes are these names used; and what anchors the community's nomenclatural practices. Exploring the history of lichen naming and early ethnolichenological research, I then investigate the stakes that must be considered for any attempt to preserve, retain, integrate, or compare the knowledge contained in both academically formalized grey names and indigenous nomenclatures in a way that preserves their sourcespecific informational content.

So, why focus on lichen naming practices? Lichens have long been relied upon as a source of food (Bryoria fremontii) and used as medicine (Usnea barbata) since before Hippocrates (Llano 1948). Lichens are used as the basis of textile dyes (Roccella tinctoria and Ochrolechia tartarea) by rural communities such as the Sámi (Llano 1948), Limbu, and Sherpa (Devkota et al. 2017); and as the material from which litmus dye is derived and used an indicator of acidity or alkalinity. Initially identified as a single organism and given binomial names (Linnaeus 1753), lichens were later characterized as compound beings or 'symbionts' (Schwendener 1869). Defined as a symbiotic system, a lichen includes a fungus (mycobiont) and a photosynthetic partner (photobiont), such as algae or cyanobacteria. The standard view has been that lichens are systems that have one fungus - typically an Ascomycete or Basidiomycete 
(Brodo et al. 2001). Accordingly, the criterion for lichen stability is the presence of the same mycobiont in the lichen system and underpins classificatory practices that rely on the fungus to name lichens. The lichen symbiont, as an organic whole, is treated as a 'non-Linnaean kind' (Minelli 2019), a grouping of biological objects to which Linnaean nomenclature does not legitimately apply. Rather than a grouping with its own uniquely identifying classificatory rules, lichens are named as if they were fungi: as 'lichenizing fungi' (Nash 2008). This means that formal naming practices of the lichen symbiont rely on knowing its photobiont-mycobiont metaphysics, but also on privileging the role of certain mycobiont-symbiont partners over others (e.g. the algal or other fungal partners), in naming practices.

To be clear, the focus of this paper is on naming practices. Naming practices, rather than names themselves, are the object of investigation. I examine how lichens are named, by whom, and on the basis of what. Naming activities can be dependent upon: 1) what is hoped to be tracked by the use of a name; 2) which knowledge claims are thought to be licensed from the ability to track and name the object in question; 3) how the experimental method chosen to investigate the entity affects how it is named; 4) how the underlying ontologies that are relied upon to track the named thing shape understanding of its compositional nature; and 5) how different operational definitions used to discriminate between the object of interest and other objects influence how it is named as an individual. I suggest that the use of these kinds of epistemological and ontological claims, inferences, choices, normative evaluations, and justifications - whether they rely on formalized conventions like the ICN or are part of a particular way of life, as in the use of the Sámi nomenclature - can be understood as activities of kind-making or kinding (Kendig 2016). This is because, in both, these naming practices can be understood as different ways of reaching out into the world to linguistically grasp that to which is of interest for a particular purpose. The notion of linguistically grasping can be used to flesh out a sort of interactionist approach where the interactionism involves both the object of interest as well as the community of namers and name users. The name is grounded in the purposes for which the namer is seeking to name; the apt use of methods and tools chosen for investigating the putative kind to be named; and the responsiveness to current and past communities of nameusers. To put it another way, biological names supervene on the naming practices that people use, the ontologies they rely on to name, and the purposes for which they are naming.

In this way, naming practices provide the investigator a route to knowledge about a portion of the world. This agent-centered interactionist account can also be seen in Mazviita Chirimuuta's (2016) notion of 'haptic' realism (a perspectival approach she applies to vision research); Michela Massimi's (forthcoming) 'perspectival realism' and 'naturalized Kantianism' (Massimi 2014); Uljana Feest's (2011) 'operationist' approach to research on short-term memory, and the Anishinaabe 'perception of social-ecological environments' as described by Iain Davidson-Hunt and Fikret Berkes (2003). For Chirimuuta, the word 'haptic' is intended to elucidate a particular sort of knowledge-yielding interaction that exists between the investigator and that which is being investigated. She suggests that our knowledge is the result of our attempting to 'touch' or 'have a feel for' that particular phenomena to which we are attending. She writes, 'Because the sense of touch requires contact and purposeful exploration on the part of the perceiver, it is obvious that with touch one apprehends an extradermal reality in virtue of and not in spite of its interactive and interested nature. By analogy, perspectivalists should investigate the thesis that scientific representations inform us about the natural world in virtue of their interactive and interested qualities' (Chirimuuta 2016: 746). 
To be sure, although valuable, Linnaean names are neither the best nor the most accurate means by which to name lichens. Non-Linnaean names, such as those used in indigenous and grey nomenclatures, also provide valuable, useful, and meaningful ways of naming that reflect the interests of the communities that use them and their diverse epistemic and ontological commitments. The stability of these nomenclatures depends on how the names are created, how they are used, and what rules are followed in their naming. Because lichens have been and continue to be classified outside the Linnaean system by academic lichenologists and within indigenous communities, there is strong motivation for exploring ways that preserve these alternative naming practices and the knowledge encoded by them from different communities. I investigate whether this is possible by relying on this agent-centered interactionist approach to examine diverse lichen naming practices.

\section{Grey nomenclatures}

The use of non-Linnaean names such as Least Inclusive Taxonomic Units (LITUs), Molecular Operational Taxonomic Units (MOTUs), and the Barcode Index Numbers (BINs) of the database Barcode of Life Data Systems (BOLD) is widespread. Focusing exclusively on non-Linnaean names within academic zoology, Alessandro Minelli (2017) suggests that although these grey nomenclatures can be useful, some employ inconsistent naming techniques that lead to ambiguity and opacity. In an attempt to avoid this kind of taxonomic ambiguity whilst also wanting to preserve the use of grey nomenclatures, Minelli proposes three requirements that should be met when using non-Linnaean or non-Code compliant nomenclatures. These include: 1) develop a method to deal with diverse rules for how names are created and how they are used in order to ensure universal understanding and eliminate ambiguous naming, 2) state a procedure for determining what it is that the name refers to-whether the name refers to an individual specimen or a taxonomic rank (e.g. species, genus, family), and 3), determine the means by which to ensure "permanent association of the "grey name" with source information such as author and year for names introduced in a publication, or equivalent information, in suitable format to be specified, for unpublished database entries' (Minelli 2017: 662-663). Developing a set of rules by which non-Linnaean names used in academic zoology can be compared appears to offer one way to avoiding problems of ambiguity and opacity that inconsistent naming techniques may introduce. But would Minelli's solution work elsewhere? If there are other nonLinnaean biological nomenclatures besides those in academic zoology, would this strategy apply to these non-Linnaean names as well? And is it possible to 'permanently associate' these nonLinnaean names with the requisite source and author information and year of introduction especially when those names are from unpublished sources?

Non-Linnaean nomenclatures provide a common resource that community members may both access and contribute to as a collaborative repository for items described in terms of such things as their functional use, ecological habitat, or molecular characteristics. Although the labelling of these entities includes widely used descriptive terms, items in grey and provisional nomenclatures are not classified according to any overarching formally structured terminology. I contend this is true of a variety of institutionalized grey nomenclatures but also of a range of indigenous biological nomenclatures, (e.g. Nuaulu classification of palms, Sámi lichen 
taxonomy), and in global repositories of biological parts such as those relied upon in synthetic biology, (e.g. Synthetic Biology Open Language, Sequence Ontology, iGEM Registry). ${ }^{1}$

In the following, I explore the range of naming practices that fall into the category of 'non-Linnaean'. As such, I extend discussion of the non-Linnaean botanical nomenclatural practices that are in use beyond institutionalized academic environments to include the naming practices used within indigenous communities. In particular, I investigate the histories, philosophies, and ethnologies of lichen naming. I rely on various non-Linnaean lichen naming practices to serve as a series of case studies to investigate how names come to carry the meaning they have for the communities that use them. In particular, I am interested in exploring how the use made of, and the value attributed to the objects named is both cause and effect of their ontological status in the community. After exploring these, I then go on to discuss the feasibility of Minelli's $3^{\text {rd }}$ requirement for grey names; evaluate whether taxonomic comparison among names across different ontologies is desirable; and investigate whether synonymy across different names or naming practices is possible.

\section{The 1950 Amendment to the International Code of Botanical Nomenclature}

Studying the history of lichen naming practices as they have been academically institutionalized, reveals that although lichens are understood to be composite systems that include a mycobiont and a photobiont (Nash 2008), the role these bionts play in lichen nomenclatural practices has changed. Although lichens were conceived of by some biologists such as Heinrich Anton de Bary, Albert Bernhard Frank, and Melchoir Treub as symbionts following Simon Schwendener's dual theory of lichens in 1869, other prominent lichenologists such as James Crombie and Wilhelm Nylander resisted Schwendener's new metaphysical characterization as well as the role of the mycobiont in lichen naming ${ }^{2}$. Prior to the 1950 revision of the Code, the use of lichen specific names was common practice and one that was gaining strength. Seeking to ensure this convention would continue, Bruce Fink (1911) went so far as to campaign, writing to 75 American and 75 European botanists and lichenologists to ask: 'Should the Lichen be maintained as a distinct class of plants or should they be distributed among the Fungi?' Charles Plitt writes, 'Of the 115 replies [Fink] received, 19, or about 17\%, favored distribution; 14, or about 12\%, thought that Lichens might be distributed, but for one reason or other prefer that they should remain a distinct group. In other words, $83 \%$ of the 115 believe that Lichens should be maintained as a distinct group.. [and the] lichenists [were] nearly unanimous in favor of maintaining the group Lichens' (Plitt 1919: 84). ${ }^{3}$

Fink was not alone. Others, such as Eugen Thomas (1939), suggested that lichen symbionts be assigned a specific nomenclature that was distinct from the nomenclature of their fungal or algal partners. Thomas' specific recommendation was: 'use the lichen name only as a name for the lichens. The lichen fungi are to be named by the genus name of the lichen with the ending -myces and the species name of the lichen in the genitive. Due to ambiguity, the term 'Gonidia' is used to denote the lichen algae' (Thomas 1939: 200).

\footnotetext{
${ }^{1}$ Although an elaboration of grey nomenclatures in synthetic biology is beyond the scope of the present paper, a focused discussion of the individuation and comparison of synthetic parts and synthetic kinds across different repositories including SBOL and Sequence Ontology can be found in Kendig and Bartley 2019.

${ }^{2}$ For a detailed history of the dissent and uptake of Schwendener's dual hypothesis of lichens, see Honegger 2000.

3 For other objections to the 1950 revision to the Code, see also especially Ciferri and Tomaselli 1955:190-192.
} 
Alternative naming practices, like Thomas' were ultimately rejected and the convention for naming lichens as separate from their fungal or algal partners was halted in 1950, when an amendment to the International Code of Botanical Nomenclature (ICN) anchored the nomenclature of the lichen symbiont to its fungal partner (Ahlner 1950). Article 76 states: 'For nomenclatural purposes names given to Lichens shall be considered as applying to their fungal components...' (Ahlner 1950: 809). This means that for the purposes of naming, lichens should be considered as if they were fungi. Despite early and continued criticism of the lichen fungal naming convention, it remains the fungal and not the algal or cyanobacterial partner, that is used to name and track lichens. Simply put, for the purposes of naming, lichens are fungi.

The repeated sense that lichens are underappreciated as wholes distinct from their parts has also played out in critical discussions of lichen naming convention following the 1950 amendment to the Code. Critics claim that naming lichens with fungal names has a significant effect on how lichen symbioses are and have been studied because they emphasize the role of one of the partners in the symbiosis over the others (cf. Ciferri and Tomaselli 1955; Goward 2008a; Arnold et al. 2009; Aschenbrenner et al.; Spribille et al. 2016; Minelli 2019). For instance, reliance on fungal evolution as the basis for lichen taxonomy brings with it a set of metaphysical assumptions about the structure and physiology of the lichen, e.g., that knowledge of fungal phylogeny is sufficient for understanding the morphological and physiological differences between lichen thalli.

Despite the taxonomic privileging of the mycobiont, botanists, mycologists, and lichenologists widely acknowledge the mosaic character of lichens. They are both keenly aware of the problems that arise with a nomenclatural practice that captures the phylogenetic contribution of only one of the partners of the lichen symbiont and have extensively studied the evolutionary impact of the role of other organismal members of lichen consortia. For instance, A. Elizabeth Arnold et al. extensively studied other fungi present within the lichen system that were not the mycobiont. These 'endolichenic' fungi are also part of healthy lichens and associate closely with the algal partner within the lichen thalli but are distinct from the mycobiont (Arnold et al. 2009: 283). They found that these endolichenic fungi played a significant role in lichen evolution and speciation: 'endolichenism appears to have served as an evolutionary source for transitions to parasitic/pathogenic, saprotrophic, and especially endophytic states' (Arnold et al. 2009: 293). These findings trouble the naming convention in lichenology as they reveal the evolutionary impact of non-mycobiont endolichenic fungi on diverse lichen phenotypesfindings that are of taxonomic value. Following Arnold et al. 2009, more researchers (Spribille et al. 2016) have also suggested that individuation practices and criteria for identity relying on the bipartite mycobiont-photobiont view of lichens, have missed part of the lichen system that may be functionally and evolutionarily significant in ensuring lichen continuity and identity over time. Their research into the composition of the lichen symbiont has led to a further shift in the way taxonomic information considered appropriate for use in classifying lichens is valued. Lichens cannot be understood as composed of just two partners - an algal or cyanobacterial partner and a fungal partner, but also include a host of others. As such, the endolichenic fungi, insofar as they play an evolutionary role in the lichen system, would also count as essential partners. The role of these additional partners may be significant. Another - a basidiomycete yeast - as well as a host of lichen-specific heterotrophic bacteria that are responsible for morphological diversity in the lichen cortex by maintaining the lichen's shape and structure, also appear to play essential roles in the lichen system (Spribille et al. 2016). Reliance on the mycobiont's fungal evolution as the basis for lichen taxonomy also brings with it a set of 
metaphysical assumptions about the structure and physiology of the lichen, e.g., that knowing the phylogeny of the fungal partner is sufficient for understanding the morphological differences between lichen thalli and their diverse physiologies. This metaphysical assumption seems to be one that runs counter to these recent findings from both Arnold and Spribille showing the evolutionary role of endolichenic fungi on both morphological diversity and maintenance of lichen structure.

Although I have largely focused on problems arising from the privileging of one biont over another, there are many other ontological commitments in addition to these that may influence choices about how lichens are studied, for example, more general assumptions concerning lichen constitution. Lichen constitution has been conceived of in at least four different ways: 1) as a consortium that is made up of epibionts, numerous photobionts and mycobionts; 2) as the construction of fungi that are exploiting a different metabolic option available to them by using the photosynthetic properties of algae or cyanobacteria; 3 ) as the construction of algae which are using the fungi, who are obligate symbionts; or 4) as an evolutionary nexus possessing parts that are constant from one generation to the next (Goward 2008b: 159-161). Although not described as such in the literature, these perspectives on lichen constitution seem to rely on varying commitments to, for example, process or substance metaphysics. These metaphysical commitments influence how lichens are identified and tracked as being the same or different. So what one takes to be the identity conditions for lichenhood is shaped by their commitment to, say, a process metaphysical approach, like option \#2. For example, consider the Pelt lichens. Panther Pelt is usually referred to as Peltigera britannica, following the name of its fungal partner. However, Peltigera britannica is part of two very different lichens_-Panther Pelt and Deciduous Pelt. In Panther Pelt, the photobiont is the cyanobacterium Nostoc, whereas for Deciduous Pelt it is the alga Coccomyxa. But this assessment of the two forms or 'morphs' as being two morphs of the same lichen-Panther Pelt described as the cyanomorph and Deciduous Pelt, as the chloromorph-depends on whether one relies on a commitment to process metaphysics or not. That is, if the lichen's evolutionary history and source of diversity is viewed as a process, then Pelt lichens can be conceived of as those that continually change photobiont partners. The processual approach also seems to suggest a phylogenetic perspective, where Peltigera britannica is taken to pick out one species, whereas on a substance approach, Deciduous Pelt and Panther Pelt are taken to be two subspecies being composed of discrete lichen systems (one possessing Coccomyxa and the other, Nostoc). Whether one considers lichens to have histories or phylogenies seems to rely on whether one's commitments are to substance or process metaphysics or something else. ${ }^{4}$ That means - harkening back to the agent-centered interactionist approach - that how one sees lichens depends on one's metaphysical commitments and importantly, these perspectives matter.

Returning once again to the 1950 amendment of the Code, the revised naming convention might strike one as peculiar since Linnaean names are often thought to be the true names or the standard for deciding what the 'real' names are for organisms. Vernacular names may be used informally, but are not accepted in the way Linnaean names are - as true names based on evolutionary relationships — rather than names that rely on morphological similarity or for a particular purpose (see McNeill et al. 2012). 'For strict followers of the [ICN], Linnaean names

\footnotetext{
${ }^{4}$ Examples of 'something else' might include Goward's 'systems' approach (similar to option \#1 above). He writes: 'lichens, like systems, have histories, yet they have no phylogenies' (Goward 2008b: 161). A processual-like approach may combine options \#2 and \#4, rely on mycobiont data and employ sequence alignment, compatibility, and phylogenetic structure to decide species identity (see, for example, Lutzoni 1997: 373-380).
} 
are the only correct names for organisms, and once determined they are assumed to be universally accepted by scientists as true names' (Barron et al. 2015: 5). Institutionalized scientific names are names that seek to be those names that people in all areas of the world can use, rather than those being useful by a particular locality, a particular set of people with a particular set of histories or interests within a specific geographical or ecological area. In short, institutionalized scientific names in general and Linnaean names in particular, are those that are thought to apply universally.

If these names only name one of the bionts within the lichen symbiont, one might argue that we do not really have a name for the whole lichen but only for part of it. This would follow if we think that the only scientifically legitimate names are those in the formal Linnaean nomenclature. But of course we have and continue to use common vernacular names as well as indigenous names for lichens. These names refer to the whole lichen - the lichen thallus. These are the names that attach to what we recognize morphologically as a lichen and are the names that are used in field guides or websites devoted to lichens and their admirers. In a statement that could be interpreted as having a clear haptic sentiment, naturalist and lichenologist Trevor Goward remarks, 'Only in common names is the human mind actually permitted unequivocally to touch the lichen thallus. Lungwort really is a lichen in the same way that Abies lasiocarpa really is a tree' (Goward 2008a: 56). Taking Goward's remark seriously, I investigate how diverse communities grasp lichens through non-Linnaean nomenclatures. I begin with the indigenous Sámi lichen nomenclature.

\section{Joegel, gadna, and lappo and the naming practices of the Sámi}

The Sámi people live on ancestral lands in what is named, the Sápmi region of Fennoscandia which comprises northern Norway, Sweden, Finland and the Murmansk Oblast of Russia and speak a Finno-Ugric language also called 'Sámi' (Valijärvi and Kahn 2017). The Sámi language reflects much of their specialized knowledge of the environment and of their relationship with the animals that they herd, trap, and fish. ${ }^{5}$ In particular, the Sámi have specialized names for the lands on which they graze their reindeer as well as for the various lichen species that can be found within these lands. These names allow the Sámi to differentiate between lichens that grow at different times during the season and between those that the reindeer eat, which they prefer, which they avoid, and which they are willing to eat in times of scarcity. Many of these names derive from their relationship with the reindeer they herd and their husbandry of them.

The Sámi language has a clear distinction between lichens and mosses. Distinguishing between these is valuable because whereas lichens are a food source for the reindeer, mosses are not (Llano 1948:19). In addition, the Sámi distinguish between different kinds of lichen both in terms of their nutritional effects on reindeer as well as where the lichens can be found. According to Jørgen Mattissen Sara (of the Sámi): 'Lappo (Alectoriae and Usneae of the beardlichen type) is not joegel, not at all, but a plant on trees just as wool or hair on beasts. The reindeer eats lappo, it is even greedy after it, it does not fatten on it, but it supports its life on it. Gadna...is everything that is affixed to stones. There is much of it on the mountains and the

\footnotetext{
${ }^{5}$ Sámi society is structured around a village assembly called a siida. The siida is instrumental in distributing winter and summer reindeer pasture areas; designating migration paths between the pasture areas; and upholding customs and rules that reflect the needs of the community in connection to the changing lands, environment, and natural resources (Ahrén 2004: 67-70).
} 
peninsulas and the islands in the Northern Finmark. The reindeer eats it if no other lichen or grass is found' (quoted by Nissen, in Lynge 1921: 244), and Aslak Larsen Siri notes, 'the most important is soakke-lappo... The reindeer eats it, but in our districts there is not so much birch (Betula odorata) that it may become plentiful' (Nissen, in Lynge 1921: 244-245).

Kristian Nissen, researcher and member of the reindeer grazing commission from 19091912, collected many of the specialized Sámi lichen names and naming practices for an extensive appendix included in Bernt Lynge's 1921 Studies on the Lichen Flora of Norway by interviewing Sámi, including Jørgen Mattissen Sara and Aslak Larsen Siri. Nissen identifies each of the Sámi interviewed; including their name, settlement status, origin when interviewed, and former or current (if different from when interviewed) region: 'From Kautokeino: The settled Laplanders ${ }^{6}$ Jon Larsen Gaino and Mikkel Anderssen Bongo, the settled, formerly nomadic Laplander Nils Persen Tornensis, the nomadic Laplanders Jørgen Mattissen Sara (now in Alta), and Aslak Larsen Siri, and some young nomadic Laplanders who served as soldiers in Alta in 1914. From Karasjok: The settled Laplanders Klemet Klemetsen, John Olsen, and Marit Eriksdatter, and the nomadic Laplanders Per Jonsen Maasø (now in Polmak) and Per Johannes Forshom. From Porsanger: The settled Laplander Anna Kristine Samuelsdatter in Lakselv. From Polmak: The settled Laplanders Aslak Johnsen, Aleknjarg and John Henriksen, Baateng' (Nissen, in Lynge 1921: 239).

The Finmarken Sámi group the lichen names into three categories: joegel, gadna, and lappo reflecting their interests in reindeer husbandry. 'Joegel' refers to the arbuscular field lichens that reindeer eat. 'Gadna' (the word roughly translates to 'dandruff') refers to scaly lichens such as those living on stones or trees that were also eaten by reindeer. And 'lappo' refers to the hairy-looking beard-lichens that grew on trees. Lappo are also eaten by reindeer but are a less-favoured food source than either the gadna or joegel (Nissen, in Lynge 1921: 240). Within each of these categories, joegel, gadna and lappo, there are particular sub-kinds. For instance, among the joegel, there are botka-joegel (which is also sometimes referred to by its synonym nallo-joegel) [angelica lichen], duolbba-joegel (whose synonym is lasta-joegel) [flat lichen], hoesta-joegel [horse lichen], krukko-joegel [jar lichen], ranes-joegel [grey lichen], sammal-joegel [moss lichen], sarva-joegel [elk lichen], smarvve-joegel [crisp lichen], ullo-joegel [wool lichen] (Nissen, in Lynge 1921: 240-241).

The anchoring of lichen names to local ecologies is especially evident among lichens in the categories, gadna and lappo which both refer to the habitats within which the lichens can be found. For instance, goeage-gadna refers to gadna lichens that grow on stones, whereas muorra gadna refers to those that grow on trees (Nissen, in Lynge 1921: 242). Those of the category, lappo refer to the arboreal habitats of the beard lichen by referring to the tree that it can be found growing on, e.g. soakke lappo [birch beard lichen ${ }^{7}$ ], boecce lappo [pine beard lichen], and guossa lappo [spruce beard lichen]. But within these, there are also further distinctions that are made in terms of texture. Sámi informant, Aslak Larsen Siri, reports a difference between various types of lappo, saying, 'boecco lappo is slightly coarser than guossa lappo' a contrast

\footnotetext{
${ }^{6}$ Although widely used in historic studies by English speakers, the use of 'Lapplanders' or 'Lapps' to refer to the Sámi people is now considered to be derogatory. The use of these terms has been avoided in all but historic quotations.

${ }^{7}$ The inclusion of the name of the tree, (e.g. spruce, birch), other host, (e.g. stones) on which the lichen is growing as part of its name, (e.g. the spruce beard lichen) guossa lappo is not exclusive to the Finmarken Sámi. These nomenclatural practices speak to both the relationship of lichen to host but also reflect the underlying ontological relationships between host, habitat, lichen and ecosystem within the community.
} 
Nissen suggests is between Alectoria Fremontii and Alectoria jubata ${ }^{8}$ (Nissen, in Lynge 1921: 242).

This terminology, and the knowledge contained within it, furnishes a means by which reindeer pastures can be differentiated by the siida in a way that is responsive to both changing environmental conditions and interests of reindeer herders. It does so by providing a way of predicting when and where certain lichens are to be found. For instance, Jørgen Mattissen Sara describes how the grazing lands respond to fire as well as noting the predictable succession of lichens that grow there following a fire: 'Nallo-joegel is the first lichen that grows up when lichens regenerate on a field that has been destroyed by fire. It is the initial lichen. Then duolbbajoegel and next smarvve appear, and out of smarvve, toppa-joegel or oaivve-joegel grows forth' (Nissen, in Lynge 1921: 243). In this way, Sámi lichen naming practices provide more than the means by which to discriminate between different kinds of lichen in terms of the nutrient value they afford and thereby furnishing a means by which to care for and maintain reindeer herds. They also provide the means for ecosystem management by supplying an understanding of fire ecology; the order of lichen regeneration; and the implementation of conservation measures. In terms of the latter, Sámi protect precious lichen fields during harsh winters by moving their herds during these periods of time where overgrazing could endanger them (Llano 1948: 16-19). Although originating from Sámi indigenous knowledge, the practice of moving herds during periods of extreme winters was one that become (much) later nationally recommended as a strategy against overgrazing (US Department of Agriculture, Alaska, 1929).

\section{Cudbear to clò-mòr: preparation, use, and cultural value of lichen dyes among the Scots}

Lichens can be found in tropical, alpine, tundra, polar, and coastal terrestrial habitats in all seven continents (Lutzoni and Miadlikowska 2009). Because of their worldwide availability, different peoples living in diverse climates have found that lichens provide a much-needed resource, employing them as food source for themselves, their herds or livestock, material for bedding, fuel for burning, as the basis of medicinal tinctures, the preparation of spirits, the source of dyes, and as pollution monitors. Both institutional academic uses as well as indigenous or other culturally-specific uses have influenced non-Linnaean naming practices among diverse communities. For instance, tracking may be the primary goal for some communities. Tracking activities are particularly helpful if what is being tracked is hard to identify, that needs differentiation from other similar appearing organisms, or is of particular value or significance to a community. Local or culturally-specific uses may also motivate naming practices. Providing names for the lichens themselves or for products that utilize lichens might be of economic or ritualistic value. These may also depend on how the lichen is prepared in the production of other products. One early systematic review provides a compendium of the then current and historic uses of lichens by North American First Peoples as a source of food and material for clothing, but also from those peoples in Scandinavia, Scotland, and Russia (Llano 1948). Included within the review are traditional Sámi and Scots lichen names for lichens that could be used as food to be consumed whole, but also as a fermentation agent and ingredient for beer-making and breadmaking. Also included are the Scots use of lichen as a traditional fabric dye, (especially those

\footnotetext{
${ }^{8}$ Alectoria fremontii and alectoria jubata are synonyms of Bryoria fremontii (Mycobank at http://www.mycobank.org/BioloMICS. aspx?TableKey $=14682616000000067 \&$ Rec $=289965 \&$ Fields $=$ All accessed June 20, 2019).
} 
used in the production of Harris Tweed), and the Dutch and French use of the lichen blue red dye Litmus. Details of the highly culturally-specific processes of production as well as the ways in which different peoples prepare and use the dye are provided.

In the review, George Llano focuses much of his attention on the most well-known of the lichen dyes. He writes, 'Of all the lichen dyes used by man, none has attained greater historical and commercial importance than those of the Roccellaceae, variously known to the English as Orchella Moss, Orchella Weed, Orchil Paste or Orchil Liquor; to the French as Orseille; and to the Germans as Persis' (Llano 1948: 33). The names for these dyes differ in each community and language family especially in terms of their commercial use. For instance, 'Orchil' is the English name, 'Cudbear' is the Scots name, and 'Litmus' ${ }^{\text {'9 }}$ is the Dutch name for the same lichen-based products that furnish blue and red dyes. Their use has a long history. Writing in 1824, De Avellar Brotero speaks of the economic importance of the dye and its use in the pigmentation of fabrics and papers (i.e. wool, silk, cotton); the basis of paint colors; a dye used in foodstuffs as well as liqueurs, pills, and oil (De Avellar Brotero 1824, cited in Llano 1948: 35). The methods of preparation of the Roccella dye were diverse, varying across cultures. For instance, regional producers of Orchil Paste (Roccella tinctoria) began by first, 'reducing [it] to a powder by passing it through a sieve... the mass was [then] moistened slightly with stale urine, the mixture being stirred once a day with additions of soda for five or six days at a temperature of $35^{\circ}$ to $45^{\circ}$ C. Fermentation proceeded and was checked frequently until the coloring matter, a dove grey, ceased to increase..[whereas] modern methods are based on more accurate knowledge of the chemistry of the lichen dye' (Llano 1948: 36). The use of human urine was not uncommon as it provided the only source of ammonia. Llano notes however that the chemical constitution of the urine did affect the resulting dye, 'Hence, I have been informed that some English manufacturers who continue to use this form of ammiacal solution, have learned by experience to avoid urine from beer-drinkers, which is excessive in quantity but frequently deficient in urea and solids, while it is abundant in water' (Lindsay 1854:40). The local Scots preparations of the Cudbear lichen (Ochrolechia tartarea) relied upon tacit and explicit knowledge-sharing about where to gather the Cudbear, in what quantities, and how to acquire and keep the ammiacal solutions. The knowledge of the local processing practices as well as the need for sourcing the requisite ammonia necessary to produce the lichen dyes were particular to rural Scotland, especially in Aberdeenshire (Llano 1948: 37). In the small subsistence farms or 'cotters', there were barrels, that were filled with urine which was collected as a resource necessary for dye-making. In these, the women of the cotter [also called crofters], would use the urine to macerate the lichens, which they named 'crotal' or 'crottle' 10 , in order to begin the production of dyes for woollen garments. Llano writes, 'The usual practice was to boil the lichen and woollen cloth together... in the urine-treated lichen mass until the desired color, usually brown [orange or deep red], was obtained. This took several hours, or less on the addition of acetic acid, producing fast dyes without the benefit of a mordant or fixing agent. The color was intensified by adding salt or saltpetre. This method was prevalent in Scotland for handwoven woollen [cloth]...known as 'tweel', in Scots Gaelic, 'clò-mòr' [big cloth], or best known to the [woollens] trade as 'Harris Tweed”' (Llano 1948: 37).

\footnotetext{
${ }^{9}$ The preparation of litmus requires that gypsum or chalk is added to the dye so that it can be cast into cubes called 'lacunus'. To use the lacunus, one dissolves the cube in water. A piece of paper is introduced to the solution which soaks up the liquid. It is the paper 'litmus paper' that is the product of this process (Llano 1948: 39).

${ }^{10}$ The Scots crotal was initially described by Carl Linnaeus as Lichen saxatilis in 1753 and later by Erik Acharius as Parmelia saxatilis in 1803. The other lichen species often used was Parmelia omphalodes (Acharius 1803).
} 
Included within the regional naming practices and preparations, ethnological descriptions fleshed out the relationship of the Scots' practices to the regional ontology. There were numerous cultural meanings attached to the lichens, their preparations of it, and in the lichendyed cloths, and the use of clothing made from these. Different lichens yielded different dye hues. For instance, lichens from the rocks near the Outer Hebrides yield a dye that is the hue of misty brown. While in their boats, the Scots fishermen avoid wearing clothing or using cloths that were dyed light brown from these lichens due to a belief that "what is taken from the rocks will return to the rocks' (Campbell, National Geographic Magazine, February, 1947 as quoted in Llano 1948:37).

5. Naming practices and valuations of lichens among the Sherpa, Limbu, Lama and Rai

In a recent paper, Devkota et al. (2017) discuss 16 vernacular names for lichens among the Sherpa, Limbu, Lama, Tamang, and Rai groups in Nepal. Lichen are used in six different ways, for medicine, ritual and spiritual purposes, food, decoration, bedding materials, and ethnoveterinary uses. Despite their varied uses, the most common name for lichen is, 'Jhyauu' which translates to 'unnecessary stuff', and 'Jhulo' which translates to 'brittle things for the ignition' (Devkota et al. 2017: 15-16). Apart from these general names, there were also names that were descriptive of morphological characteristics of the lichen and their palatability (Devkota et al. 2017: 15-18). Names widely used among these particular indigenous groups also include, ' 'Yangben' [used by the Limbu and Rai groups], 'Maangmaa' (edible) [used by the Sherpa and Lama] 'Myann' (inedible) [used by the Sherpa], and Dankini Chyau (Witch mushrooms ${ }^{11}$ ) [used by the Nepali]' (Devkota et al. 2017: 15-16).

Purposes and valuations of the whole lichen are contained in the names and naming practices of the Sherpa and Lama. For instance, 'Maangmaa' is used to refer to forms of lichen they use as a foodstuff (Everniastrum nepalense, E. cirrhatum and Parmotrema cetratum). The naming activities associated with Maangmaa also contain information and knowledge about how to prepare the lichen as an ingredient in the preparation of other foods. One of these uses is in breadmaking where the lichen is boiled, then dried, and then made into a powder-like flour that is combined with another flour (e.g. wheat or barley flour) in the proportion of one measure of lichen to three measures of wheat or barley flour) (Devkota et al. 2017: 16). The naming practices and use of (different) lichens for reindeer husbandry, breadmaking, and textile dyes by the Sámi and Scots, (reported in Llano's review in 1948), and by the Sherpa, Lama, Limbu, Rai and Tamang groups (reported in Devkota in 2017), may also provide information into the chemical constitution of these lichens. In a Scientific American article following publication of Spribille et al 2016 which provided additional evidence of the crucial role of a basidiomycete yeast in some lichen symbionts, Toby Spribille speculated about the possibility that the presence of the yeast was something that was long-known about outside of academia. He claimed that Stuart Crawford had 'collected writings from around the world-ancient Egypt, modern Mexico, medieval Russia, the Middle East, a European cookbook from the 1950s — of people using lichens to make bread and alcoholic beverages using them explicitly for leavening and fermentation. On some level, people knew that lichens contained yeast or functioned like yeast' (Gies 2017: 57). Although the comment was admittedly speculative, it does shine a light on the wealth of knowledge of the uses and affordances of certain lichens. It at least adds additional

\footnotetext{
${ }^{11}$ Dankini Chyau was a name that referred to what was taken to be a mushroom. The formal name used in scientific nomenclature is Thamnolia vermicularis, referring to a lichen (Devkota et al. 2017: 16).
} 
motivation for investigating and possibly trying to compare the epistemological, practical, and ontological activities in use outside of institutional academic environments. Attending to the naming activities, valuations, and the practices of bread-making and beer-making may reveal that some of what are thought to be recent 'discoveries' in academic lichenology (e.g. that some lichens contain not only a fungal partner and an algal partner but also a Basidiomycete yeast), were already known and contained in the naming practices of some indigenous communities. The Sámi, Sherpa, Lama, Limbu, Rai and Tamang groups' naming practices and uses of lichens might provide insight into the nature of lichen symbiotic metaphysics embedded in the use of certain lichens as leavening agents in local culinary practices.

Considering the wealth of knowledge possessed by these diverse communities contained in these nomenclatures, one might consider that studying the indigenous naming practices and the use made of lichens might (if investigated further) provide information that could help institutional academic lichenological research, e.g. contribute to a better understanding of the role of the yeast in lichenization. In addition, as some techniques are no longer widely in use in some communities, historic ethnolichenological research may provide the potential to further corroborate the evidence that the yeast was not due to 'contamina[tion], but had evolved with the other partners for more than 200 million years [and] was present in 52 other genera of lichen' (Gies 2017: 56). ${ }^{12}$ Identifying this kind of interactive, haptic knowledge requires understanding the ways in which lichens are used, what cultural value they have, and how different practices and ontologies have contributed to the naming practices used within a particular community. These practices might include, but would not be limited to, species identification, lichen preparation, culinary practices, and spiritual rituals. What may be learned from these practices is not just what is the name for a particular lichen or its constitution, but why this lichen is sonamed by the community, how naming practices inform and shape the nomenclature, and how the nomenclature and the community's ontology encodes relevant information and knowledge about the local ecology.

\section{6 'How Coyote Happened to Make the Black Moss Food'}

Knowledge of the properties of certain lichens may be acquired in the teachings of one community member to another when they are shown how to select certain species of lichen, how to prepare them once found, and why they are valuable in bread-making. The name of the lichen that provides a source of food may also be embedded in the community's ontology, contained in their narratives, and encoded in their nomenclatures. One example of this encoding of ontology into naming practices can be found by looking at the Okanagan narrative about the lichen, 'Squillip'.

One of the most widely discussed lichens within ethnobotany is what is, in North American English, colloquially called 'Black tree lichen', 'Black moss', or 'Edible horsehair lichen' (Bryoria fremontii) (Brodo et al. 2001). Black tree lichen (B. fremontii) is morphologically nearly identical to Bryoria tortuosa. The thalli of both lichens are fibourous dark-brown to black-coloured entangled strands that hang from coniferous species of trees,

\footnotetext{
${ }^{12}$ Investigating this suggestion would require an understanding of not only whether the yeast possesses the capacity for fermentation, but also the methods that local groups make use of when preparing lichen for bread making and whether, for instance, in those preparations where the lichen is first boiled, the yeast would need to be able to survive the boiling process to function as an agent of fermentation.
} 
having the appearance of hair that has been caught in the branches. Among First Peoples of North America, the Secwepemctsin name 'Wila' (given by the Secwepemc peoples) is perhaps the most widely used. The Nez Perce use the name 'Hóopop' as well. This lichen and its name and origin is also of particular value to the Okanagan, and among other Interior Salish Peoples who call it 'Squil-lip' (Dove 1933: 124).

Among the Interior Salish Peoples, the lichen was widely thought to be the braided hair of the hero trickster, Coyote (Sin-ka-lip'). Mourning Dove (Hu-mis'-hu-ma), an Interior Salish ethnographer and writer who collected many of the narratives of the Northern Plateau peoples, shares an Okanagan story of Coyote (the trickster) and his son capturing two white swans ( $\mathrm{si}$ mil'-ka-meen) (Dove 1933). In this story, the two swans try to fool Coyote and his son, Top'-kan, into thinking that they were dead so as to later surprise the trickster. Coyote, secures the swans by tying them to Top'-kan while he climbs up a pine tree to gather the pitch-top as kindling to make a fire. Just as he is at the very top of the pine tree, the swans stop pretending to be dead and start to fly off. Coyote tries to jump from the tree top, but his long hair braid catches on the branches of the pine. He swings helplessly unable to untangle his hair, as the birds fly away with his son still tied to them. When high in the air, the swans cut the ties, leaving Top'-kan to fall to his death ${ }^{13}$. Coyote then takes out his flint knife and releases himself from the tree by chopping off his hair braid and finally dropping to the ground. He then looks up at his long, twisted hair, dangling from the branches of the pine and says, 'You shall not be wasted, my valuable hair. After this you shall be gathered by the people. The old women will make you into food'. Dove then explains, 'that was Coyote's ruling near the Beginning. That is why his hair, the long black timber-hair, hangs from the trees in the mountains. It is called Squil-lip. It is the black moss that people cook in pit-ovens' (Dove 1933: 124). Although Dove's first language is Salish, she records the narrative in English for the collection, The Coyote Stories, as 'How Coyote Happened to Make the Black Moss Food'. Dove translates the Salish, 'Squil-lip' to 'Black moss', but was well aware that the English vernacular name might confuse readers into thinking that Squil-lip was a moss and not a lichen. In a footnote that extends over two pages, she informs the reader, "This "Black moss" is a pendulous lichen, a species of Usnea. It grows on trees and bushes in the mountains. From a short distance it looks very much like unkempt black or dark hair. Palatable and nutritious when cooked, it is considered a delicacy by the Indians' (Dove 1933: 125). Dove details the process of preparing Squil-lip and the practice of cooking it in stone-heated pits. She specifies that these pits are 'eighteen inches to four feet deep and three to six feet in diameter' and describes the composition and layering of the pit (green grass, layer of camas roots, Squil-lip, and then more green grass or leaves with tule-reed matting overtop). In addition to describing the techniques and complete explanations of the cooking procedure, she also includes in the narrative, that only the Squil-lip will taste 'sweet' and not 'bitter' (Dove 1933: 124-125).

'How Coyote Happened to Make the Black Moss Food' provides the meaning to the biological name, 'Squil-lip', insofar as it explains not only the value of the lichen for the people, its use, purpose and preparation. But the narratives also provides a means of teaching people how to tell the difference between Squil-lip, and other species of lichen. This is invaluable knowledge as the Black tree lichen, (Bryoria fremontii), is morphologically nearly identical to Bryoria tortuosa, but the latter contains vulpinic acid and is poisonous which the former rarely contains. It is only Bryoria fremontii that is used as a food source by the Okanagan, Nez Perce, Thompson, Lillooet, and Shuswap Interior Salish. Despite the morphological similarity and ecological

${ }^{13}$ Top'-kan's life is restored by Coyote, so he does not stay dead. 
overlap of the species, these cultures can easily tell the difference between them. ${ }^{14}$ When gathering the Squil-lip but before a large quantity is harvested, a small amount of the lichen was tasted to tell if it was indeed the edible 'sweet' Squil-lip or the inedible 'bitter' poisonous lichen (Bryoria tortuosa): 'Among the Okanagan, young hunters would collect small pieces of the [yetto-be-definitively-identified lichen] from different mountain slopes during their travels and bring them back for their grandmothers or mothers to taste. If it was "sweet" and not bitter, the family would claim the area where it was growing and collect as much of the lichen as possible from the trees in the vicinity' (Turner 1977: 467). In addition to being able to identify $B$. fremontii from $B$. tortuosa, those of the Nez Perce group also observed that the lichen from young trees was more bitter than from mature trees, and those found near rivers were less well-flavoured than those from the mountains indicating the presence of vulpinic acid (Turner 1977: 467).

\section{Are different naming practices and nomenclatures comparable?}

Although ethnobotanical literature on lichen naming practices and their use in a variety of cultures appears to provide an important resource for further understanding of lichens outside of these cultures, a number of questions arise as to how this literature can (and should) be used. ${ }^{15}$ First, we may ask: how is knowledge and information encoded within different naming practices - whether in the form of grey nomenclature used in institutional lichenology or in indigenous naming practices - retained when compared? Attempting to answer this question requires studying how information is coded in different communities and how names and naming practices are anchored in the ontologies of those communities.

Careful examination of all of the above cases of lichen naming practices suggests that lichen nomenclatures rely on both epistemic and ontological commitments as well as cultural and economic values. These diverse commitments and values make unifying the naming practices and the names that result from these in different communities into one set of synonyms or the formation of an inter-translatable database, such as the one suggested by Minelli in response to problems with grey nomenclatures, difficult. Of course, one purported early goal of ethnobotany was to do exactly that - to map so-called folk nomenclatures onto scientific nomenclatures - by suggesting that both 'scientific' biology and 'folk' biology are underpinned by the same biological basis (Atran 1990; Berlin 1992). Finding consilience in their nomenclatural systems, for instance in identifying similar properties, e.g. transitivity, ranking was thought to be evidence for their inter-translatability. But the problem is not that these systems do not display transitivity or ordered rankings that can be compared to one another. As Roy Ellen (2016) points out, this consilience obscures the ways in which these nomenclatures are used.: "the way people interact and experience plants in traditional... societies is rather different from the way a taxonomist in the Kew Herbarium interacts with them' (Ellen 2016: 13). This is not to say that a universal

\footnotetext{
${ }^{14}$ As well as providing a source of food, B. fremontii and other species of Bryoria lichen were also used as fabric to create clothes and shoes; as a source for yellow dye; an ingredient in an infection-preventing ointment; and a cure for indigestion and diarrhoea (Turner 1977, 465-466).

${ }^{15} \mathrm{But}$, posing the problem in this way already assumes something about the nature of these nomenclatures: that comparing names and naming practices across diverse communities in ways that preserve their meaning is actually possible. Discussing whether or not this assumption is justified is of course an option and provides a useful entry point into philosophical discussions of how knowledge may (or may not) be ineliminably bound to a particular culture's ontology. Whether the assumption is justified might rely in large part on what one considers valuable about nomenclatural synonyms.
} 
scheme that accommodates different taxonomies is impossible, it just means that this exemplifies only one purpose for ethnobiology. It captures the information from indigenous names that may be necessary to compare them to institutionalized formal naming conventions as synonyms, but it does not capture all of the information that is contained within indigenous names.

Translating an indigenous lichen nomenclature, such as the Sámi’s, into institutionalized scientific nomenclature, is possible. But the translation sometimes misses out on how someone is naming when they use the indigenous name. Put another way, there might be something different about the way in which the classifier is naming, e.g. they may be finding knowledge in a different way that is lost when what is intended is simply a translation of one organism name in one nomenclatural system to that in another. Assigning a name is one goal of a naming system but names and naming practices may also encode meaning and value that outstrips a simple description of the name as a convenient or pragmatically useful label. Ellen discusses this problem in terms of the indigenous naming practices that are used for palms among the Nuaulu people in Indonesia rather than in terms of indigenous lichen naming practices of the Sámi, Sherpa, and Okanagan as I have done. ${ }^{16}$ Studying the names of palms used by the Nuaulu reveals that their nomenclature includes names for palms from 13 scientific genera and 14 species (Ellen 1998, 2016). The Nuaulu rely on 15 uninomials and 36 binomials. 14 of these names refer to sago palms (Ellen 2016). Ellen (2016) observes, 'formally-speaking, it would be possible to compare how Nuaulu classification of palms conforms to the Linnaean categories, how it relates to Berlin's universalist scheme of ranks,... [h] owever,...the picture of Nuaulu vernacular classification...constitutes a set of features and relations that the Nuaulu linguistic and ethnographic data permit us to yield; they do not conform to any pseudo-Linnaean local ontology' (Ellen 2016:14).

But of course, Nuaulu names are, and have been used alongside Linnaean ones. In earlier discussions of the Sámi and of the Okanagan names, I also included the current institutionalized academic names. This practice is widespread in ethnobiological literatures. But we might ask what does this practice assume about the nature of the two names? Although the names are usually treated as synonymous with each other, we might still want to inquire into the nature of the relationship that exists between the indigenous names and the institutionalized academic names that are purported to be the synonyms. We may ask whether the mention of both names alongside each other is a linguistic act that explicitly suggests the two names are intertranslatable. Discussing the potential for the intertranslatability of Nuaulu palms, Ellen argues that when the indigenous name is translated into the Linnaean name, there can be an erasure of the Nuaulu knowledge associated with the name. Although it is possible to overlay Nuaulu palms on to a nomenclature based on phylogeny or compare indigenous naming systems to phylogenetic-based naming systems in a way that leads to knowledge of a particular sort, this does not mean that we have a complete translation of the Nuaulu name into the Linnaean name. Ellen suggests that we need to be aware of what kind of thing we can come to know by this translation and what sort of knowledge we are generating when we do this.

Both institutional and indigenous nomenclatural practices provide criteria that allow us to name and track the things to which we are interested in identifying for a range of purposes. Does this mean that we can - at least in theory-compare names and the kinds to which they refer across naming systems? I argue that this depends on whether the epistemological and ontological

\footnotetext{
${ }^{16}$ Although I focus on Sámi, Sherpa, and Okanagan lichen naming practices as forms of non-Linnaean grey classification that are largely based on functional and specific uses endemic to those using these for a variety of purposes, I think my application of grey classification can also be applied to Nuaulu palm and rattan classifications.
} 
commitments we rely upon to attribute synonymy to these corresponds to how these names are used. In order to compare a Nuaulu name with a Linnaean name, we also need to identify what is motivating the choice to compare these two names. Only by first considering these commitments would it be possible to decide the nature or extent of their synonymy. ${ }^{17}$

Moving from palms to lichens, this would mean that reliance on one naming system or framework (e.g. a phylogenetic-based nomenclature) to ground the claim of synonymy of some names may not be appropriate for a particular study. If what is sought is knowledge of how the indigenous name came to be used, then what is of interest would be to discover, for instance, how the Okanagan narrative 'How Coyote Happened to Make the Black Moss Food' provided the meaning to the biological name, 'Squil-lip'. A synonym based on phylogeny, like Bryoria fremontii, although generally useful, would not contain any information about how it is identified by the elders, what meanings are attached to it, and what narratives the Okanagan use to talk about it. But of course, the Linnaean name was never intended to do that. In order to make a claim of synonymy between two names that is apt for the study at hand, it would be necessary to focus attention on one aspect of the name or naming practice and bracket off other meanings or aspects of it in order to make the comparison. If what was of interest was to compare different indigenous names for lichens (e.g. like those of the Sámi, Sherpa, or Okanagan), what would be required would be knowing what was the reason for comparison. This would then determine what properties to include and what not to include in the comparison. This in turn requires understanding how the different communities anchor names and ground kinds using their different ontologies. Comparing names across naming systems is possible. But the translation required to do so often leads to substantial information loss if the epistemological and ontological commitments relied upon to make the comparison do not reflect the interest in comparing these names in the first place. This is because comparison is not among whole ontologies but always between partitionings of these, e.g. those that circumscribe what is of interest to a particular study. Synonyms are therefore not synonymous in all contexts but are delimited perspectivally: they are dependent upon who it is that is comparing the names as potential synonyms; what ontological commitments they hold; and for what reason is the comparison sought. This is because lichen knowledge is often expressed in terms of multiple interacting relationships: the relationship between the lichen and the environment or place of its origin; and the relationship between the namers, the place, and the lichens that reside there (cf. Davidson-Hunt et al. 2005:189-191).

\section{Biological names supervene on naming practices and the ontologies of namers}

By focusing on diverse naming practices, I have tried to show how the names and naming practices relied upon by different communities - whether indigenous or academically institutionalized - rely on the epistemologies, ontologies, and values of the communities of namers that use them to track those objects of interest in the world. Talking about grey nomenclatures has provided a way to investigate the ontologies and values of different communities that have either intentionally or accidentally adopted non-Linnaean nomenclatures for the purpose of biological naming. The examples in the above show how diverse nomenclatures depend not only on different purposes and naming practices but also on different epistemological and ontological commitments. One might respond sceptically to my discussion of the diversity of naming practices among the Sámi, Sherpa, Scots, Okanagan and users of the

\footnotetext{
${ }^{17}$ This is, of course, a general problem and one that is not exclusive to ethnobotanical studies.
} 
ICN by saying that there really isn't a problem here because everybody already knows that nomenclatures are influenced by naming practices and purposes. They might suggest that we can accommodate these different naming practices by simply adopting a pluralist approach to lichen naming as just being dependent on the purposes of namers. I hope that I have shown why this pluralist approach does not go far enough. The solution to the diversity of naming practices cannot be accommodated by a mere 'the more the merrier' approach to lichen nomenclature. These different nomenclatures, (Linnaean, non-Linnaean grey, Sámi, Sherpa, and Okanagan), are more than merely influenced by the distinct purposes and aims of people using different ontologies. Biological names are determined by and necessarily co-vary with the naming processes that are used by a particular community. These naming practices are themselves informed by the ontology used by the community to name. In addition, in some cases-like in the Sámi binomials and the Okanagan Squi-lip - they also determine why they are of interest. This ineliminable interactivity of biological namers, naming communities, community ontologies, and the objects of nomenclatural interest can perhaps best be understood in terms of a supervenience relationship. Biological names supervene on the naming processes that particular peoples use, the ontologies they rely on to name, and the purposes for which they are naming. The relationship of supervenience is therefore between the nomenclature and the naming practices, ontology of the community, and the values and purposes for the naming held by the namers. This supervenience relationship is a much thicker ${ }^{18}$ notion than the thinner influencer relationship — that nomenclatures are influenced by naming practices and purposes - often used to defend the adoption of a pluralist approach to diverse nomenclatures.

One consequence of this thicker supervenience relationship is that it seems to trouble the assumption that institutionalized and indigenous naming practices can be clearly demarcated. In defense of the clear demarcation, a potential opponent of my supervenience view might argue that it doesn't really apply to institutionalized naming practices because the use of naming in those is 'merely' pragmatic and therefore not problematically ontology-laden ${ }^{19}$. I argue that this sentiment underpins much of the justification for why institutionalized names are often widely accepted as being globally applicable and those that are indigenous are considered ontologyheavy, and therefore only locally applicable. But of course this view can itself be understood as an ontological commitment. The frequent claim that only Linnaean names are 'scientific' or that scientists use institutionalized names in 'merely' pragmatic ways is worth briefly investigating. Linnaean taxonomy, grey nomenclature and indigenous nomenclatures all provide informative ways of understanding the objects of interest, but they do so in different ways as the identification of something being of interest depends on what it is that is attended to, for what reason, and within what ontology. ${ }^{20}$ This means that all of these are value-laden perspectives

\footnotetext{
18 This 'thick' notion of ontology refers to the entire worldview or system of beliefs held by a particular community. It includes the suite of epistemological and metaphysical commitments that are learnt, interacted with, passed on, and have and continue to shape thinking and practice that rely on them. Nomenclatures are just one part of the worldview, the meaning of which is inextricably linked to the system of beliefs and practices. One cannot switch between these thick notions of ontology like one might be able to switch between the thin notions of ontology as simple untethered nomenclatures.

${ }^{19}$ The claim that ontological commitments can be eschewed in favor of a 'merely pragmatic' or otherwise epistemology-only account has been popular among many philosophers and biologists when discussing both species concepts (Rosselló-Mora \& Amann 2001: 53-60; Ereshefsky 2010: 111-113) and natural kinds (Magnus 2012: 4849; Slater 2015: 396, 402-403). For criticisms of these pragmatic and epistemology-only views see Martinez 2017 and Kendig and Grey 2019/2021).

20 That a name is pragmatically useful may mean different things at different times within a community. At one time, what might be pragmatically useful is to have a morphological description, whereas at a later time what is
} 
which bring with them a way of seeing that may not completely overlay other ways of seeing. The ability to linguistically grasp those biological objects of interest or use biological names for pragmatic reasons depends on one's means of interacting with the world that is through ones ontology. Claiming that one is able to opt out of an ontology-laden interaction by virtue of relying on institutionalized scientific naming conventions 'just for pragmatic reasons' does not mean one is not relying nonetheless on an ontology. To make sense of what 'pragmatic usefulness' means for that community of namers would require some not insubstantial ontological framework. This is because knowing that a name is pragmatically useful depends on the naming practices and ontology of the naming community that sees it as useful in this way.

\section{Concluding remarks}

The purpose of this paper was to contribute to the discussion of the role of different ontologies of name users in philosophy of ethnobiology. ${ }^{21}$ I achieved this by investigating different alternative lichen nomenclatures, focusing in particular on the naming activities used within communities of indigenous namers. The main claim, fleshed out in the case studies of the naming practices of the Sámi, Sherpa, Okanagan, and those relying on the lichen conventions set out by the ICN, was that these naming practices tether lichen names to the value and role of lichens as they are used in a particular way of life, study, or way of being in the world. As a label that is affixed to something, the meaning and import as well as the informational content of lichen names such as Squil-lip, Maangmaa, soakke lappo, and Cudbear, is grounded in the ontology of the namers or name-users. My suggestion - that names supervene on naming practices and the ontologies of namers - is meant to provide a means by which to investigate naming practices. Doing so would provide a number of potential intellectual deliverables by facilitating a way to investigate how information contained in a particular set of naming practices originated and is contributed to over time; how revised meanings are made accessible to the community; how these might (possibly) be translatable to those holding different ontologies or using different nomenclatures; and how the information contained within naming practices that are grounded in different ontologies might be appropriately and usefully compared.

Investigating different alternative lichen nomenclatures, my focus has been on the particular naming activities used within diverse communities of namers and users of those names. For this reason, I began with a general philosophical exploration of what naming provides for a community. I explained that biological nomenclatures furnish a means by which biological entities can be identified, referred to, and used within a community. I showed how names identify types of entities that one interacts with and relies upon in one's way of life. Following this general discussion, institutional naming practices were broached and Minelli's conception of non-Linnaean grey nomenclatures introduced. That was where I made the tentative suggestion that the notion of grey nomenclature need not only apply within institutionalized academic environments but may also apply to botanical nomenclatures in use within indigenous

more useful is to have a way of identifying an evolutionary object of investigation: 'Increasingly, [the ICN] has come to emphasize names as tools for identification, rather than purely as descriptions of species. This shift stems from the current reordering of taxonomies according to evolutionary relationships rather than morphological similarities' (Barron et al. 2015: 5).

${ }^{21}$ Ludwig (2016) contributes significantly to the discussion of ontology in ethnobiology. The approach taken in this paper is intended to directly complement both his as well as Ellen's $(1998,2016)$. 
communities. Motivating this extension, I pointed to some of the naming conventions and controversies that have occurred over the history of lichen naming since Schwendener's dual theory of lichens. In particular, I concentrated my attention on the 1950 revision to the ICN, the one that recommended lichen names be anchored to the nomenclature of the fungal partner of the lichen fungal-algal/cyanobacterial symbiont. This convention means that names that refer to whole lichens (rather than merely to one part), such as both those used in indigenous nomenclatures and vernacular usage, do not comply with the 1950 revision and so could also be considered instances of grey nomenclatures.

The history and ethnography of lichen naming practices offers a valuable case study for those interested in the interplay of ontological, epistemological, and valuative commitments shaping diverse taxonomic systems. As a study in ethnobotany or ethnobiology, my aim has not just been to show how lichens have been labeled with traditional Linnaean nomenclature, fungal names, analogical terms, functional terms, technological terms, morphological terms, and spiritual terms. The intention was also to show how the meaning-containing but non-Linnaean nomenclatures used to annotate lichens vary across communities and the ontologies they use. I showed how this ontology-ladenness has implications for any attempt to compare nomenclatures. Biological meaning expressed in indigenous and institutionalized names may not be wholly comparable — or translatable — across different naming practices. I dismissed one argument often given to explain this incomparability - the justification that indigenous naming practices are those that attribute purpose, intent, and design to the items that are named, whereas institutional naming practices (at least purport to) avoid describing the kinds they name in such ontologyladen teleological terms. I countered this argument, revealing how the claim that institutional nomenclature provides a value-free approach to naming or that it is 'simply pragmatic' is itself the product of ontological framing that is necessary to make sense of why this pragmatic approach is valuable. Biological nomenclatures - whether they be academically institutionalized or indigenous - rely on an array of ontological commitments and valuations ${ }^{22}$.

Acknowledgments

I wish to thank Kyle Powys Whyte, David Ludwig, my fellow symposiasts and audience as the 2019 ISHPSS in Oslo, the members of the Centre for Ethics and Law in the Life Sciences (CELLS) at Leibniz Universität Hannover, the audience at my MSU Interdisciplinarity Colloquium, and the anonymous reviewers for their invaluable comments on various iterations of this paper.

Work cited

Acharius E (1803). Mehodus qua Omnes Detectos Lichenes Secundum Organa Carpomorpha ad Genera, Species et Varietates Redigere atque Observationibus Illustrare Tentavit Erik Acharius. Stockholm: Ulrich.

\footnotetext{
${ }^{22}$ Valuations, such as which partner of the lichen symbiont should be relied upon for naming is just one of the ways assessments of taxonomic value is present in institutional nomenclatures.
} 
Ahlner, S. (1950). Some aspects of nomenclature and taxonomy of lichens. In H. Osvald H, E. Åberg (eds.) Proceedings of the 7th International Botanical Congress. Stockholm: Almquist \& Wiksell.

Ahrén, M. (2004). Indigenous peoples' culture, customs, and traditions and customary law-the Saami people's perspective. Arizona Journal of International and Comparative Law 21 (1): 63-112.

Arnold, A., Miadlikowska, J., Higgins, K., Sarvate, S., Gugger, P., Way, A., Hofstetter, V., Kauff, F., Lutzoni, F. (2009). A phylogenetic estimation of trophic transition networks for ascomycetous fungi: are lichens cradles of symbiotrophic fungal diversification? Systematic Biology 58: 283-297.

Aschenbrenner I., Cernava T., Berg G., Grube M. (2016). Understanding microbial multi-species symbioses. Frontiers in Microbiology 7:180.

Atran, S. (1990). Cognitive Foundations of Natural History: Towards an Anthropology of Science. Cambridge: Cambridge University Press.

Barron, E., Sthultz, C., Hurley, D., Pringle, A. (2015). Names matter: Interdisciplinary research on taxonomy and nomenclature for ecosystem management. Progress in Physical Geography 1-21.

Berlin, B. (1992). Ethnobiological Classification: Principles of Categorization of Plants and Animals in Traditional Societies. Princeton: Princeton University Press.

Bowker, G. (2000). The game of the name: Nomenclatural instability in the history of botanical informatics. In: M. Bowden, T. Hahn and R. Williams (eds) Proceedings of the 1998 Conference on the History and Heritage of Science Information Systems. Pittsburgh: 7483.

Bowker, G. and Star, S. (1999). Sorting Things Out: Classification and its consequences. Cambridge, MA: MIT Press.

Brodo, I., Sharnoff, S. D., and Sharnoff, S. (2001). Lichens of North America. New Haven: Yale University Press.

Chirimuuta, M. (2016). Vision, Perspectivism, and Haptic Realism. Philosophy of Science 83: 746-756.

Ciferri, R., Tomaselli, R. (1955). The symbiotic fungi of lichens and their nomenclature. Taxon 4:190-192. 
Davidson-Hunt, I., Berkes, F. (2003). Learning as you journey: Anishinaabe perception of socialecological environments and adaptive learning. Conservation Ecology 8(1): 5.

Davidson-Hunt, I., Jack, P., Mandamin, E., Wapioke, B. (2005). Iskatewizaagegan (Shoal Lake) Plant knowledge: an Anishinaabe (Ojibway) Ethnobotany of Northwestern Ontario. Journal of Ethnobiology 25(2):189-227.

Devkota, S, Chaudhary, R., Werth, S., Scheidegger, C. (2017). Indigenous knowledge and use of lichens by the lichenophilic communities of the Nepal Himalaya. Journal of Ethnobiology and Ethnomedicine 13 (15): 1-10.

Dove, M. (1933). How Coyote happened to make the black moss food. In Coyote Stories. Caldwell: Caxton Printers Ltd. pp., 119-126.

Ellen, R. (1998). Palms and the Prototypicality of Trees: Some Questions Concerning Assumptions in the Comparative Study of Categories and Labels. In L. Rival (ed.) The social life of trees. Oxford: Berg. pp. 57-79.

Ellen, R. (2016). Is there a role for ontologies in understanding plant knowledge systems? Journal of Ethnobiology 36 (1): 10-28.

Ereshefsky, M. (2001). The poverty of the Linnaean hierarchy: A philosophical study of biological taxonomy. Cambridge: Cambridge University Press.

Feest, U. (2011). Remembering (Short-Term) Memory: Oscillations of an Epistemic Thing. Erkenntnis 75: 391-411.

Fink, B. (1911). The nature and classifications of lichens-I. Views and arguments of botanists concerning classification. Mycologia 3(6): 271-282.

Gies, E. (2017). The Meaning of Lichen. Scientific American (June): 52-59.

Goward, T. (2008a). Twelve readings on the lichen thallus. II. Nameless little things. Evansia: 25(3): 54-56.

Goward, T. (2008b). Twelve readings on the lichen thallus. VII. Species. Evansia 26 (4): $153-$ 162.

Honegger R. (2000). Simon Schwendener (1829-1919) and the dual hypothesis in lichens. Bryologist. 103 (2): 307-313.

Kendig, C. (2016). Activities of kinding in scientific practice. In C. Kendig (ed.) Natural Kinds and Classification in Scientific Practice. Abingdon \& New York: Routledge, 1-13. 
Kendig, C., Bartley, B. A. (2019). Synthetic kinds: kind-making in synthetic biology. In J. R. S. Bursten (ed.) Perspectives on Classification in Synthetic Sciences: Unnatural Kinds. London: Taylor \& Francis, pp. 78-96.

Kendig, C., Grey, J. (2019/2021). Can the epistemic value of natural kinds be explained independently of their metaphysics? British Journal for the Philosophy of Science 72 (2): 359-376. https://www.journals.uchicago.edu/doi/10.1093/bjps/axz004

Linnaeus, C. (1753). Species plantarum, exhibentes plantas rite cognitas, ad genera relatas, cum differentiis specificis, nominibus trivialibus, synonymis selectis, locis natalibus, secundum systema sexuale digestas. Holmiae, Impensis Laurentii Salvii. L. Salvius, Stockholm.

Lindsay, W. (1854). Experimental researches on the tinctorial properties of lichens. Edinburgh New Philosophical Journal. p. 40.

Llano, G. (1948). Economic Uses of Lichens. Economic Botany 2(1): 15-45.

Ludwig, D. (2016). Overlapping Ontologies and Indigenous Knowledge. From Integration to Ontological Self-Determination. Studies in History and Philosophy of Science Part A 59: $36-45$.

Lutzoni, F. (1997). Phylogeny of Lichen- and Non-Lichen-Forming Omphalinoid Mushrooms and the Utility of Testing for Combinability among Multiple Data Sets. Systematic Biology 46 (3): 373-406

Lutzoni F., Miadlikowska J. (2009). Lichens. Quick guide. Current Biology 19: R502-R503. https://doi.org/10.1016/j.cub.2009.04.034 (Accessed 4 July 2019).

Lynge, B (1921). Studies on the lichen flora of Norway. Kristiania: I kommission hos J. Dybwad. http://hdl.handle.net/2027/mdp.39015061871961 (Accessed 2 Feb 2019).

Magnus, P. D. (2012). Scientific Enquiry and Natural Kinds: From Planets to Mallards. London: Palgrave Macmillan.

Martinez, E. J. (2017). Stable Property Clusters and Their Grounds. Philosophy of Science 84: 944-55.

Massimi, M. (forthcoming). Perspectival Realism. New York: Oxford University Press.

Massimi, M. (2014). Natural Kinds and Naturalised Kantianism. Nô̂s 48 (3): 416-449. 
McNeill J, Barrie F, Buck W, Demoulin, V. Greuter W, Hawksworth D, Herendeen, P, Knapp S, Marhold, K. Prado, J. (2012). International code of nomenclature for algae, fungi, and plants (Melbourne Code), Koenigstein: Koeltz Scientific Books.

Minelli, A. (2017). Grey nomenclature needs rules. Ecologica Montenegrina 7: 654-666.

Minelli, A. (2019). The galaxy of the non-Linnaean nomenclature. History and Philosophy of Taxonomy as an Information Science. History and Philosophy of the Life Sciences https://link.springer.com/article/10.1007/s40656-019-0271-0 Accessed 1-10-2019.

Nash, T. (ed.) (2008). Lichen biology. Cambridge: Cambridge University Press.

Nissen, K. (1921). Appendix: Lapposian lichen. In B. Lynge's Studies on the lichen flora of Norway. Kristiania: I kommission hos J. Dybwad. http://hdl.handle.net/2027/mdp.39015061871961 (Accessed 2 Feb 2019).

Plitt, C. (1919). A Short History of Lichenology. The Bryologist 22 (6): 77-85+xii.

Rasmussen D., Akulukjuk, T. (2009). 'My Father was Told to Talk to the Environment First before Anything Else': Arctic Environmental Education in the Language of the Land. In M. McKenzie, P. Hart, H. Bai, and B. Jickling (eds.). Fields of Green: Restorying Culture, Environment, and Education. New York: Hampton Press. pp. 279-292.

Rosselló-Mora, R., Amann, R. (2001). The species concept for prokaryotes. FEMS Microbiology Reviews 25: 39-67.

Schwendener, S. (1869). Die Algentypen der Flechtengonidien. Schultze. Basel.

Slater, M. (2015). Natural Kindness. British Journal for the Philosophy of Science 15 (66): 375411.

Spribille, T, Tuovinen, V., Resl, P., Vanderpool, D., Wolinski, H., Aime, C., Schneider, K., Stabentheiner, E., Toome-Heller, M., Thor, G., Mayrhofer, H., Johannesson, H., McCutcheon, J. (2016). Basidiomycete yeasts in the cortex of ascomycete macrolichens. Science 353(6298):488-492.

Thomas E. (1939). Über die Biologie von Flechtenbildnern. Bern: Buchdruckerei Büchler \& Co. p. 200.

Turner, N. (1977). Economic Importance of Black Tree Lichen (Bryoria fremontii) to the Indians of Western North America. Economic Botany 31 (4): 461-470.

Valijärvi, R-L, and Kahn, L. (2017). North Sámi: An Essential Grammar. London and New York: Routledge. 
